\title{
Antibacterial Effects of Galla Rhois Extract against Streptococcus suis Infection in Mice
}

\author{
Chun-Nam Cha', Eun-Ah Yu' ${ }^{2}$, Eun-Kee Park ${ }^{3}$, Hyunju Choi ${ }^{4}$, Suk Kim ${ }^{5}$, and Hu Jang Lee ${ }^{5 *}$ \\ ${ }^{1}$ Engineering Research Institute, Department of Industrial Systems Engineering, \\ Gyeongsang National University, Chinju 600-701, Korea \\ ${ }^{2}$ Tongyeong National Quarantine Station, Ministry of Health \& Welfare, Tongyeong 650-110, Korea \\ ${ }^{3}$ Medical Humanities and Social Medicine, College of Medicine, Kosin University, Busan 602-703, Korea \\ ${ }^{4}$ Elderly Life Redesign Institute, Department of Biomedical Laboratory Science, Inje University, Gimhae 621-749, Korea \\ ${ }^{5}$ Institute of Animal Medicine, College of Veterinary Medicine, Gyeongsang National University, Chinju 600-701, Korea
}

(Received January 23, 2013/Revised January 29, 2013/Accepted March 27, 2013)

\begin{abstract}
Streptococcus suis (S. suis) is a major swine pathogen and an emerging zoonotic agent and is an increasing public health problem across Asia. The present study was undertaken to estimate the antibacterial effect of GR extract and therapeutic effect of GR extract against $S$. suis infection in mice. At the concentration of GR extract $2.5 \mathrm{mg} / \mathrm{ml}$, the antibacterial effect was not shown on S. suis. However, the antibacterial effect against $S$. suis was observed at the concentration of GR extract $5.0 \mathrm{mg} / \mathrm{ml}$. Oral administration of GR extract at the dose of $10 \mathrm{mg} / \mathrm{kg}$ showed a therapeutic effect for $S$. suis infected BALB/c mice. The mortality of GR extract-treated mice at the concentration of 5,10 and $20 \mathrm{mg} / \mathrm{kg}$ was $80 \%, 70 \%$, and $50 \%$ at 12 days, respectively, while that of untreated mice was $100 \%$ at 8 days after a lethal dose of S. suis infection. The results of our study strongly indicate that GR extract has potential as an effective for $S$. suis infection in mice.
\end{abstract}

Key words: Galla rhois, methanol extract, Streptococcus suis, antibacterial effect, mouse

\section{Introduction}

Streptococcus suis (S. suis) is a gram-positive bacterium distributed world-widely that causes meningitis, endocarditis, septicemia, septic arthritis, pneumonia, and abortion in pigs and humans ${ }^{1}$. In intensive swine industry, S. suis infection is causing considerable economic losses and animal health care problems for the pig farming industry worldwide ${ }^{2}$. The natural habitat of $S$. suis is the upper respiratory tract and the intestinal tract ${ }^{3,4)}$. In adult pigs, carriage of $S$. suis is usually asymptomatic but colonized sows can infect their piglets after nasal or oral contact $t^{5}$. Newborn pigs can also become infected during parturition when they contact, swallow or aspirate $S$. suis from sow vaginal secretions ${ }^{6}$. In young pigs, $S$. suis infection causes a wide variety of diseases, including meningitis, septicemia which are the main causes of mortality ${ }^{7}$. As an emerging zoonotic pathogen, S. suis can be transmitted to humans by direct contact ${ }^{8-10)}$. S. suis is also

*Correspondence to: Hu-Jang Lee, College of Veterinary Medicine, Gyeongsang National University, 900 Gajwa-dong, Chinju 660-701, Korea

Tel: 82-55-751-6642, Fax: 82-55-751-5803

E-mail: hujang@gnu.ac.kr emerging as a serious zoonotic pathogen of humans particularly in South East and East Asia where it is one of the most common causes of human meningitis ${ }^{11,12}$. In 2005 , a large outbreak of 215 cases $S$. suis infections occurred in Sichuan, China, resulting in 38 deaths ${ }^{10}$. $S$. suis from pigs was thought to be the origin of the outbreak.

At present, prevention and control of the disease are based on the use of the autogenous vaccine and antibiotics ${ }^{1}$. Prior to the emergence of $S$. suis strains, penicillin was the original choice of treatment ${ }^{13)}$. Then, macrolides and fluoroquinolones, such as erythromycin, tylosin and enrofloxacin, were considered as the effective substitutes for penicillin because $S$. suis isolates are historically highly susceptible to these drugg ${ }^{14)}$. However, some of the commonly used antibiotics such as erythromycin and enrofloxacin for treatment and prevention of $S$. suis infections in pigs are becoming less efficient, due to an increase in resistance among $S$. suis isolates in recent years ${ }^{1,15-17)}$.

Conventional herbal medicines have long been used as remedies against infectious diseases in Asian countries including Korea and China, and may be an alternative treatment to S. suis infections ${ }^{18-20)}$. Galla Rhois (GR) has long been used in traditional Asian medicine to treat diarrhea, persistent coughing and spontaneous perspiration in man 
because this product has antidiarrhetic, astringent and hemostatic properties. GR is a harmless natural material that contains a number of tannin-derived components, including methyl gallate and gallic $\operatorname{acid}^{21,22}$. Gallotannins are a class of hydrolysable tannin polymers formed from gallic acid, which has antifungal and antiviral properties ${ }^{23,24}$. Methyl gallate and gallic acid have a recognized growth-inhibiting activity against Escherichia coli and Streptococcus spp. and does not negatively influence the growth of lactic acidproducing bacteria ${ }^{25-27}$.

However, the antibacterial activities of GR against $S$. suis is unknown. In this study, the antibacterial effects of GR extracts against $S$. suis were investigated in vitro and in vivo.

\section{Materials and Methods}

\section{Bacteria and culture}

S. suis (KVCC-BA0700673)) was obtained from the Korean Veterinary Culture Collection (Anyang, Korea). The cultures were incubated in brain heart infusion (BHI) broth (Difco Laboratories, Detroit, USA) for 18 hours at $37^{\circ} \mathrm{C}$. The stock organism was stored in BHI broth containing 50\% glycerol at $-80^{\circ} \mathrm{C}$ for later use.

\section{Preparation of GR extracts}

GR powder was obtained from GS Bio (Jeonju, Korea), who produced the powder from dried plant material and analyzed its components as previously described ${ }^{25)}$. Briefly, one $\mathrm{kg}$ of plant material dried in an oven at $60^{\circ} \mathrm{C}$ for three days was twice extracted with methanol at room temperature, the residue was removed by filtration (Toyo filter paper no. 2, Toyo Roshi Kaisha, Ltd., Tokyo, Japan) and the filtrate was concentrated using vacuum rotary evaporation (Iwai Co., Tokyo, Japan) followed by freezing dry to powder. The GS extracted powder was suspended into a $1,000 \mathrm{mg} / \mathrm{ml}$ stock solution. The stock solution was then used to prepare various test solutions by diluting with distilled water. The composition of the crude extracted powder was analyzed using chromatography on a silica gel column (70-230 mesh; Merck, Darmstadt, Germany) and fractionation on a preparatory high-performance liquid chromatography column (Delta Prep 4000, Waters, Ontario, Canada). Tannins account for $45.8 \%$ of the total composition of GR, and methyl gallate and gallic acid comprised $16.4 \%$ and $4.3 \%$ of that, respectively.

\section{Determination of antibacterial activity}

Bacteria were diluted with phosphate-buffered saline (PBS) solution (pH 7.4) to $2 \times 10^{4} \mathrm{CFU} / \mathrm{ml}$, added in different concentrations $(1.0,2.0,5.0 \mathrm{mg} / \mathrm{ml})$ of GR extract, and incubated at $37^{\circ} \mathrm{C}$ for $0,2,4$, and $8 \mathrm{~h}$. After incubation and proper dilution, $1.0 \mathrm{ml}$ of each solution was plated onto agar medium supplemented with $2 \%(\mathrm{v} / \mathrm{v})$ newborn bovine serum (Difco Laboratories, Detroit, USA) to assess bacterial colony-forming units (CFUs).

\section{Animal challenge test}

Forty 6-week-old female BALB/c mice (average body weight, $20.7 \pm 0.6 \mathrm{~g})$ purchased from Samtako Bio Korea Co. Ltd. (Osan, Korea) and were acclimated for one week. All mice were randomly divided into four groups (10 mice per group). The experimental groups were treated orally three times per day for 14 days with the following solutions: control group, sterile saline; group 1, GR extract $5 \mathrm{mg} / \mathrm{kg}$ body weight; group 2, GR extract $10 \mathrm{mg} / \mathrm{kg}$ body weight; group 3, GR extract $20 \mathrm{mg} / \mathrm{kg}$ body weight. The mice were housed in a room at a temperature of $22 \pm 3^{\circ} \mathrm{C}$, a relative humidity of $40-70 \%$, and a 12 -h-light/12-h-dark cycle with free access to mouse chow and water. All animal procedures were approved by the Institutional Animal Care and Use Committee of Gyeongsang National University (GNU-LA2013-18) in Korea. On the day of the experiment, all mice were challenged with a lethal dose of $2 \times 10^{9} \mathrm{CFU}$ of $S$. suis in $0.1 \mathrm{ml}$ phosphate buffered saline (PBS) with intraperitoneal injection. After bacterial infection, the control group was orally treated with $0.1 \mathrm{ml}$ of sterile PBS and the treated groups were orally treated with GR extract 5, 10 and $20 \mathrm{mg} / \mathrm{kg}$ body weight every $24 \mathrm{~h}$ during 12 days, respectively. All mice were observed for 12 days for morbidity and mortality.

\section{Statistical analyses}

The data were analyzed by a one-way analysis of variance (ANOVA), followed by Student's $t$-test. The results are expressed as mean $\pm \mathrm{SD}$. A mean difference was significant at the 0.05 level.

\section{Results and Discussion}

\section{Determination of antibacterial activity}

Antibacterial effect of GR extract against $S$. suis is presented in Fig. 1. At $2 \mathrm{~h}$ after incubation, inhibition of $S$. suis growth in the group treated with $5.0 \mathrm{mg} / \mathrm{ml} \mathrm{GR}$ extract was significantly lower than that of control (no treatment) ( $p<$ 0.001 ). At $4 \mathrm{~h}$ and $8 \mathrm{~h}$ after incubation, inhibition of $S$. suis growth in the group treated with 2.0 and $5.0 \mathrm{mg} / \mathrm{ml} \mathrm{GR}$ extract was significantly lower than that of control $(p<$ 0.001 ), but the number of bacterial cells in the group treated with $1.0 \mathrm{mg} / \mathrm{ml} \mathrm{GR}$ extract was increased depending on the incubation time. At the concentration of $5.0 \mathrm{mg} / \mathrm{ml}$, the bacteriocidal effect of GR extract was observed on S. suis. Ahn et al. ${ }^{25)}$ reported that GR-derived tannins (methyl gallate and gallic acid) at the concentration of $10 \mathrm{mg} /$ disc inhibited 


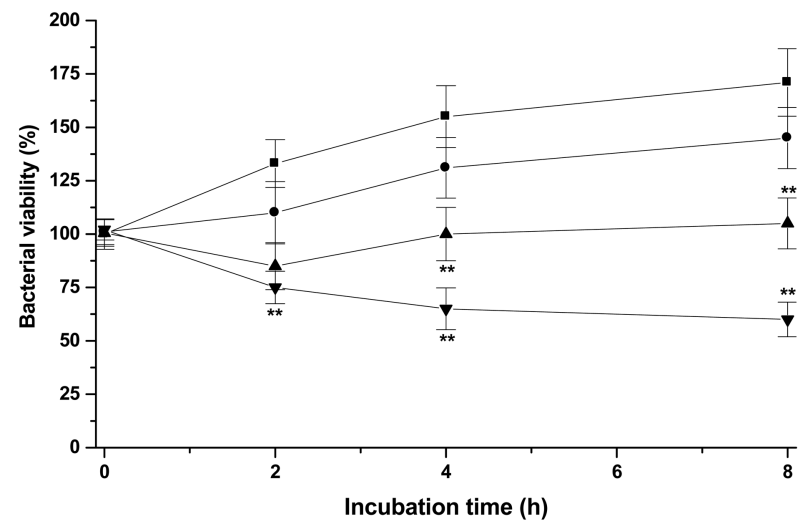

Fig. 1. Antibacterial effect of GR extract against $S$. suis. GR extract diluted with PBS was used at the concentration with $0(\mathbf{\square}), 1.0(\mathbf{\bullet})$, $2.0(\boldsymbol{\Delta})$ and $5.0(\boldsymbol{\nabla}) \mathrm{mg} / \mathrm{ml}$. Bacterial viability was measured based on CFUs on culture plates for three independent experiments. "Significantly different from the control $(\mathrm{p}<0.05) .{ }^{* *}$ Significantly different from the control $(\mathrm{p}<0.001)$.

the growth of Streptococcus faecalis, whereas the growth of Bifidobacterium adolescentis and Bifidobacterium longum was not affected. In addition, Gao et al. ${ }^{28)}$ reported that hot water extract of Japanese apricot fruits inhibited the growth of $S$. suis and the rage of the minimum antibacterial concentration (MIC) was 20.83-58.33 mg/ml. Furthermore, Praphrueti and Charerntantanaku ${ }^{29)}$ reported that the crude chloroform extract of Lentinula edodes showed potential inhibiting S.suis and MIC was $12.5 \mathrm{mg} / \mathrm{ml}$. Compared with the above studies, antibacterial activity of GR extract in this study may be more effective against $S$. suis.

\section{Animal challenge test}

The therapeutic effect of GR extract against $S$. suis were shown in Fig. 2. The mortality of mice infected with $S$. suis was counted during the experimental period. The mortality rate in the control group was $100 \%$ at the 8 th day after infection with $S$. suis. However, the group treated with GR extract 5,10 , and $20 \mathrm{mg} / \mathrm{kg}$ body weight survived two, three, and five mice until the 12 th day, respectively. Ma et al. ${ }^{30)}$ reported that the cure rate of mice challenged with $S$. suis was $70 \%$ after treatment of $2 \mathrm{mg} / \mathrm{kg}$ ceftiofur injection. According to the previous research by Li et al. ${ }^{31)}$, the extract of Forsythia suspensa at the dose of $41 \mathrm{mg} / \mathrm{kg}$ body weight reduced the mortality of mice infected with $S$. suis by $25 \%$. In the present study, the mortality rate of the treated GR extract at the dose of $20 \mathrm{mg} / \mathrm{ml}$ was $40 \%$, which was similar to that of the research carried out by $\mathrm{Li}$ et al. ${ }^{31)}$ with the consideration of dosage and experimental period.

In conclusion, our results demonstrate that GR extract at the concentration of $20 \mathrm{mg} / \mathrm{ml}$ takes therapeutic effect for the infection of $S$. suis in mice.

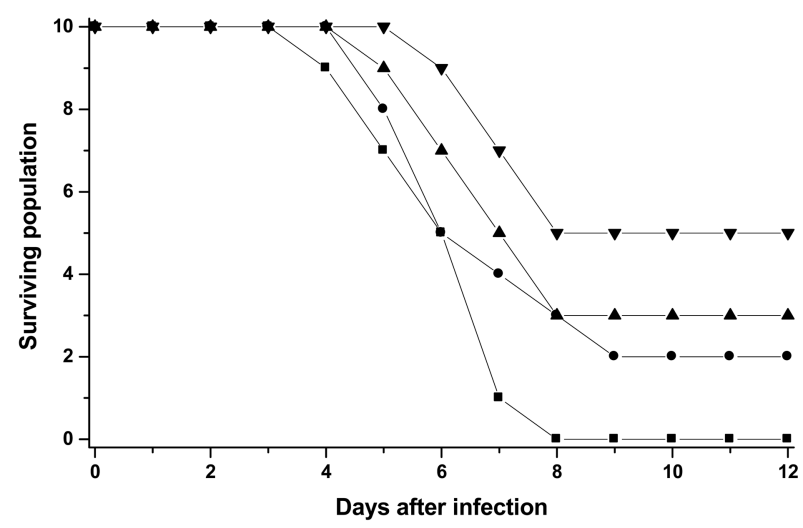

Fig. 2. Mortality rate of mice infected with $S$. suis after treatment of GR extract with different concentrations. $\mathbf{\square}$, control group treated with phosphate buffer solution (PBS); $\boldsymbol{\bullet}$, the group treated with $5 \mathrm{mg} / \mathrm{kg}$ GR extract $(\mathrm{n}=10) ; \boldsymbol{\Delta}$, the group treated with $10 \mathrm{mg} / \mathrm{kg}$ GR extract $(\mathrm{n}=10) ; \boldsymbol{\nabla}$, the group treated with $20 \mathrm{mg} / \mathrm{kg}$ GR extract $(n=10)$.

\section{Acknowledgements}

This research was supported by Basic Science Research Program through the National Research Foundation of Korea (NRF) funded by the Ministry of Education, Science and Technology (Grant No. 2010-0021247).

\section{References}

1. Wisselink, H.J., Veldman, K.T., Van den Eede, C., Salmon, S.A., Mevius, D.J.: Quantitative susceptibility of Streptococcus suis strains isolated from diseased pigs in Seven European countries to antimicrobial agents licensed in veterinary medicine. Vet. Microbiol. 113, 73-82 (2006).

2. Kin,g S.J., Heath, P.J., Luque, I., Tarradas, C., Dowson, C.G., Whatmore, A.M.: Distribution and genetic diversity of suilysin in Streptococcus suis isolated from different diseases of pigs and characterization of the genetic basis of suilysin absence. Infect. Immun. 69, 7572-7582 (2001).

3. Robertson, I.D., Blackmore, D.K.: Prevalence of Streptococcus suis types 1 and 2 in domestic pigs in Australia and New Zealand. Vet. Rec. 124, 391-394 (1989).

4. Gottschalk, M., Segura, M.: The pathogenesis of the meningitis caused by Streptococcus suis: the unresolved questions. Vet. Microbiol. 76, 259-272 (2000).

5. Sriskandan, S., Slater, J.D.: Invasive disease and toxic shock due to zoonotic Streptococcus suis: an emerging infection in the East? PLoS Med. 3, e187 (2006).

6. Amass, S.F., Clark, K.L., Knox, K., Wu, C.C., Hill, M.A. Streptococcus suis colonization of piglets during parturition. Swine Health and Prod. 4, 269-272 (1996).

7. Meijerink, M., Ferrando, M.L., Lammers, G., Taverne, N., Smith, H.E., Wells, J.M.: Immunomodulatory effects of Streptococcus suis capsule type on human dendritic cell responses, phagocytosis and intracellular survival. PLoS One, 7, e35849, 
2012.

8. Kennedy, K.J., Jadeer, A.A., Ong, C.W., Senanayake, S.N., Collignon, P.J.: Two cases of Streptococcus suis endocarditis in Australian piggery workers. Med. J. Aust. 189, 413 (2008).

9. Lun, Z.R., Wang, Q.P., Chen, X.G., Li, A.X., Zhu, X.Q.: Streptococcus suis: an emerging zoonotic pathogen. Lancet Infect. Dis. 7, 201-209 (2007).

10. Yu, H, Jing, H, Chen, Z, Zheng, H, Zhu, X., Wang, H., Wang, S., Liu, L., Zu, R., Luo, L., Xian, N., Liu, H., Liu, X., Shu, Y., Lee, S.S., Chuang, S.K., Wang, Y., Xu, J., Yang, W.: Human Streptococcus suis outbreak, Sichuan, China. Emerg. Infect. Dis. 12, 914-920 (2006).

11. Mai, N.T., Hoa, N.T., Nga, T.V., Linh, le D., Chau, T.T., Shnh, D.X., Phu, N.H., Chuong, L.V., Diep, T.S., Campbell, J., Nghia, H.D., Minh, T.N., Chau, N.V., de Jong, M.D., Chinh, N.T., Hien, T.T., Farrar, J., Schultsz, C.: Streptococcus suis meningitis in adults in Vietnam. Clin. Infect. Dis. 46, 659-667 (2008).

12. Ip, M., Fung, K.S., Chi, F., Cheuk, E.S., Chau, S.S., Wong, B.W., Lui, S., Hui, M., Lai, R.W., Chan, P.K.: Streptococcus suis in Hong Kong. Diagn. Microbiol. Infect. Dis. 57, 15-20 (2007).

13. Woodford, N., Ellington, M.J.: The emergence of antibiotic resistance by mutation. Clin. Microbiol. Infect. 13, 5-18 (2007).

14. Wang, L., Zhang, Y.: Postantibiotic effects and postantibiotic sub-MIC effects of tilmicosin, erythromycin and tiamulin on erythromycin-resistant Streptococcus suis. Braz. J. Microbiol. 40, 980-987, 2009.

15. Hendriksen, R.S., Mevius, D.J., Schroeter, A., Teale, C,; Jouy, E., Butaye, P., Franco, A., Utinane, A., Amado, A., Moreno, M., Greko, C., Stärk, K.D., Berghold, C., Myllyniemi, A.L., Hoszowski, A., Sunde, M., Aarestrup, F.M.: Occurrence of antimicrobial resistance among bacterial pathogens and indicator bacteria in pigs in different European countries from year 20022004: the ARBAO-II study. Acta Vet. Scand. 50, 19 (2008).

16. Vela, A.I., Moreno, M.A., Cebolla, J.A., González, S., Latre, M.V., Domínguez, L., Fernández-Garayzábal, J.F.: Antimicrobial susceptibility of clinical Strains of Streptococcus suis isolated from pigs in Spain. Vet. Microbiol. 105, 143-147 (2005).

17. Zhang, C.P., Ning, Y.B., Zhang, Z.Q., Song, L., Qiu, H., Gao, H.: In vitro antimicrobial susceptbility of Streptococcus suis strains isolated from clinically healthy sows in China. Vet. Microbiol, 131, 386-392 (2008).

18. Sheng, Z., Li, Y., Li, Z.: In vitro antibacterial activity of medicinal herb extracts against five drug-resistant Streptococcus suis strains. The 5th International Conference on Bioinformatics and Biomedical Engineering, Wuhan, China, pp. 1-4, 2011.
19. Wu, S., Xiao, Z., Zeng, L.: Antibacterial activities of combination of Chinese herbs with antibiotics against Streptococcus suis in vitro. J. Tradit. Chin. Vet. Med. 2009-02, 2009.

20. Han, W., Cui, B., Zhang H.: Initial study on anti-bacterial activity of Mentha spicata Linn extraction in vitro. Chin. Agric. Sci. Bull. 2010-01, 2011.

21. Chen, J.C., Ho, T.Y., Chang, Y.S., Wu, S.L., Hsiang, C.Y.: Antidiarrheal effect of Galla Chinensis on the Escherichia coli heat-labile enterotoxin and ganglioside interaction. J. Ethnopharmacol. 103, 385-391 (2006).

22. Djakpo, O., Yao, W.: Rhus chinensis and Galla chinensis-folklore to modern evidence: review. Phytother. Res. 24, 17391747 (2010).

23. Pettinari, A., Amici, M., Cuccioloni, M., Angeletti, M., Fioretti, E., Eleuteri, A.M.: Effect of polyphenolic compounds on the proteolytic activities of constitutive and immuno-proteasomes. Antioxid. Redox Signal. 8, 121-129 (2006).

24. Kratz, J.M., Andrighetti-Frohner, C.R., Leal, P.C., Nunes, R.J., Yunes, R.A., Trybala, E., Bergstrom, T., Barardi, C.R. \& Simoes, C.M.: Evaluation of anti-HSV-2 activity of gallic acid and pentyl gallate. Biol. Pharm. Bull. 31, $903-907$ (2008).

25. Ahn, Y.J., Lee, C.O., Kweon, J.H., Ahn, J.W., Park, J.H.: Growth-inhibitory effects of Galla Rhois-derived tannins on intestinal bacteria. J. Appl. Microbiol. 84, 439-443 (1998).

26. Escalante, A., Wacher, C., Farrés, A.: Lactic acid bacterial diversity in the traditional mexican fermented dough pozol as determined by $16 \mathrm{~S}$ rDNA sequence analysis. Int. J. Food Microbiol. 64, 21-31 (2001).

27. Kang, M.S., Oh, J.S., Kang, I.C., Hong, S.J. \& Choi, C.H.: Inhibitory effect of methyl gallate and gallic acid on oral bacteria. J. Microbiol. 46, 744-750 (2008).

28. Gao, Z., Shao, J., Sun, H., Zhong, W., Zhuang, W., Zhang, $Z$.: Evaluation of different kinds of organic acids and their antibacterial activity in Japanese Apricot fruits. African $J$. Agri. Res. 7, 4911-4918 (2012).

29. Praphrueti, R., Charerntantanaku, W.: Antibacterial activity of crude extract from Lentinula edodes mycelium grown in liquid media on Escherichia coli and Streptococcus suis. J. Agr. Res. Ext. 28, 21-29 (2011).

30. Ma, P., Jiang, Q., Chen, X., Hu, W., Sun, Z.: Efficacy of ceftiofur suspension experimentally induced with Streptococcus suis serotype II in mice. China Anim. Husb. Vet. Med. 37, 175-177 (2010).

31. Li, Y., Li, M., Cui, L., Sheng, Z., Cui, Y. Bian, D., Wang, M., Yan, O. The effect of ethanol extracts from Forsythia suspensa against antibiotic-resistant Streptococcus suis isolates in vivo and in vitro. The $5^{\text {th }}$ International Conference on Bioinformatics and Biomedical Engineering, Wuhan, China, pp. 1-5 (2011). 